\title{
An Investigation of Stickiness Force of Palm Oil Fruit for Food Processing
}

\author{
Sherena Saree ${ }^{1}$, Shanti Faridah Salleh ${ }^{2}$ and Mohd Azlan Ismail ${ }^{3}$ \\ ${ }^{1,2}$ Department of Chemical Engineering and Energy Sustainability, Universiti Malaysia \\ Sarawak, 94300 Kota Samarahan, Sarawak. \\ ${ }^{3}$ Department of Mechanical Engineering, Universiti Malaysia Sarawak, 94300 Kota \\ Samarahan, Sarawak \\ ${ }^{1}$ Email: sareesherena@yahoo.com, ${ }^{2}$ Email: shanti_faridah@yahoo.com, \\ ${ }^{3}$ Email:lanzmr@gmail.com
}

\begin{abstract}
Dura and tenera varieties of palm fruit are very popular in production of palm oil and palm kernel, respectively; it becomes imperative to investigate the stickiness forces of the fruit as that may affect the design of machines to handle the processing fruits and also for major agricultural crops. Thus, this study investigates stickiness behavior for the two varieties of palm fruit. An investigation was carried to study the stickiness forces in palm oil fruit for food industry. The sensitive parameters that was considered in this study are dimension of the fruit, work of adhesion, surface free energy, dynamic angle of repose, coefficient of static friction and surface tension. All listed parameters have been individually considered as the sources of stickiness force in the palm oil machinery processes. A mathematical approach takes into account all relevant parameters to predict the adhesive forces value. The mechanical and physical interactions, that would affect the formation and magnitudes of stickiness force in the palm fruit also considered. The finding from this study shows the maximum amount of adhesive forces between the fruit bunches and also between fruit and the contact surface area of the palm oil fruit industry. Apart from that, this study quantified the minimum amount of force needed to detach the fruit bunches and from body of the machine. It is believed that the outcome from this study will provide fundamental understanding on the stickiness forces of the palm fruit that may influence the cleaning and threshing performance to palm oil industries and may benefit researchers, operation engineers and project managers in food industry.
\end{abstract}

Keywords: stickiness, palm oil fruit, adhesive force.

\section{Introduction}

As stated by Malaysian Palm Oil Board (MPOB) in April 2014, Indonesia and Malaysia produce about $85 \%$ of the world's palm oil. Other producer countries such as Thailand, Columbia, Nigeria, Papua New Guinea and Ecuador also produce oil palm as one of their major economics crops [1]. Since Malaysia known as one of the largest producer of palm oil, technology development is very important to improve the number of palm fruit production. Therefore studies in food industry were taken into account and stickiness problem was recognized as one of the most popular problems occurs in food industry long time ago.

In palm oil processing operation, the Full Fruit Bunch (FFB) is gathered and transported by using tractor, lorry and conveyor system to the sterilizer unit. The sterilizer used to increase moisture

Manuscript History:

Received 23 June, 2015, Revised 8 September, 2015, Accepted 10 September, 2015, Published 30 September, 2015

e-ISSN 2289-7771

Copyright $\odot 2015$ JASPE 
of the fruit bunch and soften the fruit bunch in order to assist the thresher to thresh and separate the fruit from bunches. During thresher operation, the palm fresh fruit is moving in horizontal line as the machine rotate at constant rotational velocity. Thus, some fruit got wedge and this will reduced threshing efficiency.

Stickiness problem occur in many industries such as cereal industry, confectionary industries, dairy industries, powder industries and packaging materials industries. In cereal industry, sticky dough causes low dough mixing tolerance, reduced dough strength and also reduces dough volume [2]. Stickiness problem lower the product quality and have a very negative effects in bread making processing. Other than that, in food packaging materials the adhesion or sticking of food materials was affects consumers' confidence in the quality of the product and also lower the product utility. Adhesion or sticking food materials in food cans or packages affect consumers' confidence. Thus, it shows that stickiness problem happen not only in palm oil mill industry but also in many food industries such as cereal industries, confectionery industries, dairy industries and powder industries.

Many studies were done to investigate the mechanical and physical properties of palm fruit. A study was done by Owolarafe et. al. (2007) to determine the physical and mechanical properties of tenera and dura varieties [3]. The study focused on the physical and mechanical properties of two varieties of fresh oil palm fruit (dura and tenera). The physical properties that were investigated include, size, sphericity index, aspect ratio, true density, bulk density, and porosity. Besides, the mechanical properties were studied such as cracking force, pressure, dynamic angle of repose and also coefficient coefficient of friction of dura and tenera varieties. From the study, it was found there were distinct differences between physical and mechanical properties of palm oil fruit. Thus, this study considered important in the design of processing machine such as sterilizer, digester and also oil press.

Fatin et. al. (2014) also measures the physical and mechanical properties for Malaysia palm oil fruits[4]. The physical properties that were reported in the study include length, thickness and width. Besides, mechanical properties include the rupture force, deformation at rupture, hardness and also energy at break which is important to design a chopper blade. However, this research did not determine the stickiness force or any adhesive force between the palm fruits.

Stickiness problem occur in food industry where a number of researchers have studied about technologies and applications of stickiness in food industry. Nevertheless, until now there is no research study regarding stickiness problem in fresh fruit bunch in palm oil mill applications. Thus, the aim of this research is to investigate stickiness behavior for the two varieties of palm fruit. The outcome of this study will be very useful to determine stickiness forces that will effect palm oil process operations. It is believed the finding from this study will benefits the researchers, mill engineers, academician, manufacturing company and also machinery processing company.

\section{Research Methodology}

\subsection{Sensitive Parameters That Involved in the Stickiness Force}

This paper attempts to provide more detailed investigations regarding stickiness forces for different types of palm fruits. The selection of palm fruit is based on common palm fruits grow in Malaysia. The mathematical equation developed was investigated based on previous literature specifically focus on food industry [2-6]. There are two types of fruits which are dura and tenera varieties. Both radiuses for dura and tenera varieties are within $0.02256-0.03014$ meters and 0.02597 - 0.03336 meters respectively. All the sensitive parameters that involve in the determination of stickiness forces have been highlighted in research methodology part because it is a very crucial part in determining the values of adhesive forces. Thus, physical and mechanical properties are directly proportional to the changes of stickiness forces value. 


\subsubsection{Physical and mechanical Properties of dura and tenera varieties}

Basically, the weight of the fruit bunch ranges between $10 \mathrm{~kg}$ to $40 \mathrm{~kg}$ depends on the size and age, and the spikelet's ranges from 6 to 20 grams [4], [5]. Literature reviews have indicated that tenera has higher fruit mass compare to dura where dura has a higher tendency to have its shape towards a sphere than tenera [6]. Both tenera and dura assumed to be in oval shape in this study. Detail information for physical and mechanical properties for both dura and tenera shown in Table 1 and 2 respectively.

Table 1. Physical and mechanical Properties of dura variety[3]

\begin{tabular}{|c|c|c|c|}
\hline \multicolumn{4}{|c|}{ Dura Variety } \\
\hline $\begin{array}{c}\text { Physical } \\
\text { Properties }\end{array}$ & $\begin{array}{c}\text { Mean value (+/- } \\
\text { standard deviation) }\end{array}$ & Mechanical Properties & $\begin{array}{c}\text { Mean value } \\
\text { (+/- } \text { standard deviation) }\end{array}$ \\
\hline Length, mm & $30.25(+/-5.07)$ & \multicolumn{2}{|c|}{ Dynamic angle of repose, 0} \\
\hline Width, mm & $19.94(+/-2.64)$ & Plywood & $22.01(+/-1.51)$ \\
\hline Spericity, \% & $70.67(+/-9.27)$ & Aluminum & $21.01(+/-1.74)$ \\
\hline Fruit mass, $g$ & $7.66(+/-2.04)$ & Mild steel & $19.91(+/-2.18)$ \\
\hline $\begin{array}{l}\text { True density, } \\
\mathrm{kg} / \mathrm{m}^{3}\end{array}$ & $1112.50(+/-52.60)$ & Galvanized steel & $22.23(+/-1.28)$ \\
\hline $\begin{array}{l}\text { Bulk density, } \\
\qquad \mathrm{kg} / \mathrm{m}^{3}\end{array}$ & $659.40(+/-21.74)$ & \multicolumn{2}{|c|}{ Coefficient of friction, $\mu$} \\
\hline Density ratio, $\%$ & $59.33(+/-2.21)$ & Plywood & $0.58(+/-0.05)$ \\
\hline Porosity, \% & $40.67(+/-2.21)$ & Aluminum & $0.53(+/-0.03)$ \\
\hline & & Mild steel & $0.56(+/-0.03)$ \\
\hline & & Galvanized steel & $0.56(+/-0.03)$ \\
\hline
\end{tabular}

Table 2. Physical and Mechanical Properties for tenera Variety[3]

\begin{tabular}{|c|c|c|c|}
\hline \multicolumn{4}{|c|}{ Tenera Variety } \\
\hline $\begin{array}{l}\text { Physical } \\
\text { Properties }\end{array}$ & $\begin{array}{l}\text { Mean value } \\
\text { ( +/- standard } \\
\text { deviation) }\end{array}$ & Mechanical Properties & $\begin{array}{c}\text { Mean value } \\
(+/- \text { standard deviation })\end{array}$ \\
\hline Length, mm & $35.96(+/-4.08)$ & \multicolumn{2}{|c|}{ Dynamic angle of repose, 0} \\
\hline Width, mm & $20.15(+/-3.79)$ & Plywood & $18.43(+/-1.86)$ \\
\hline Spericity, \% & $64.23(+/-6.58)$ & Aluminium & $18.42(+/-1.98)$ \\
\hline Fruit mass, $\mathrm{g}$ & $8.50(+/-2.00)$ & Mild steel & $18.59(+/-1.27)$ \\
\hline $\begin{array}{l}\text { True density, } \\
\mathrm{kg} / \mathrm{m}^{3}\end{array}$ & $995.70(+/-26.99)$ & Galvanised steel & $18.32(+/-0.97)$ \\
\hline $\begin{array}{l}\text { Bulk density, } \\
\mathrm{kg} / \mathrm{m}^{3}\end{array}$ & $611.04(+/-27.79)$ & \multicolumn{2}{|c|}{ Coefficient of friction, $\mu$} \\
\hline Density ratio, $\%$ & $61.45(+/-4.01)$ & Plywood & $0.52(+/-0.06)$ \\
\hline Porosity, \% & $38.55(+/-4.01)$ & Aluminum & $0.52(+/-0.04)$ \\
\hline & & Mild steel & $0.52(+/-0.05)$ \\
\hline & & Galvanized steel & $0.52+/-0.03)$ \\
\hline
\end{tabular}




\subsubsection{Dynamic angle of repose}

The dynamic angle of repose of non-cohesive granular material is an important parameter affecting surface features and processes. This angle is the slope at which a given material will stabilize and come to rest [7]. Dynamic angle of repose plays important roles to the value of stickiness forces equation. Different material has different types of dynamic angle of repose where the angle was affected by the types of materials such as aluminum sheet, galvanized sheet and also mild steel sheet. There was a small difference in the coefficient of friction obtained on plywood and aluminum sheet which are (+/-0.14). Other than that, there was no significant difference in the coefficient of friction obtained on galvanized and mild steel sheet. Dynamic angles of repose for the four surfaces were practically the same.

\subsubsection{Coefficient of static friction}

In terms of coefficient of static friction, the value of galvanized steel is a little bit higher compare to other surface. This might have been due to the moderating influence of the smooth fruit surface. The lower porosity or percentage volume of voids in the tenera variety may be due to the higher sphericity and aspect ratio, which ensure a more compact arrangement of the fruits. As could be observed, the values of coefficient of static friction obtained for the tenera are closer than that obtained for the dura. An explanation for this observation could be the very smooth glossy surface of the fruit. This further explained the tendency of the tenera to have a higher smooth surface than the dura.

\subsubsection{Cracking Force and Pressures applied}

The average cracking force required to break the dura and tenera were $2301 \mathrm{~N}$ and $1149 \mathrm{~N}$, respectively. The average cracking force required to break the dura was higher than the tenera. In order to break, Dura need greater force compare to tenera. The mean pressures applied on the fresh dura variety and tenera varieties were $5.79 \mathrm{~N} / \mathrm{mm}^{2}$ and $2.00 \mathrm{~N} / \mathrm{mm}^{2}$, respectively. This information will be useful in the design of the oil press or expeller.

\subsection{Stickiness Force Equations}

The investigation of the stickiness force equations in palm oil fruit for food industry starts with the literature review and the mathematical equations constructed by using past studies [9-12]. An adhesive is a material used for holding two surfaces together[8]. There are two types of adhesive forces which are adhesive force between two spheres and also adhesive forces between the solid and liquid. In this paper, the focused is on the palm fruits where the two spheres relation refers to two oval palm fruits. Besides that, the other types of adhesive forces are between solid and liquid which refers to the palm oil fruit with the mild steel surface. 


\subsubsection{Pull off Force between 2 oval shapes}

The pull off force between two shapes is defined as the forces between two oval shapes in this case. The value of adhesive forces it is related to the work of adhesion and radius of area contact involves:

$$
F_{A}=-\frac{3}{2} \pi R \omega \text { between } 2 \pi R \omega \text { from ref [9] }
$$

Where $\mathrm{R}$ is the radius of the spheres and $\omega$ is the work of adhesion. This equation obeys DerjaguinMuller-Toporov (DMT) Theory where it accounts for the effect of surface forces just outside the contact area [9]. Israelachivili et. al. (2014) also states that the pull off force probably lies between the values lies predicted by equation (1)[10].

\subsubsection{Pull off Force between Solid and Liquid}

The adhesive force between solid and liquid was applied in this investigation, where in this paper it is referring to the fruit bunch stuck with the oil palm at the surface of the machine. Adhesive force equation for the second case was stated below in equation (2):

$$
F=4 \pi R \gamma \quad \text { from ref }[9]
$$

After that, the value of work of adhesion and also the radius of the palm fruit was determined. By referring to the Adam and Livingston (1996) the work of adhesion is defined as:

$$
\omega=2 \gamma \quad \text { from reference [10] }
$$

Where $\omega$ is the work of adhesion and $\gamma$ is the surface energy. Therefore, for these investigations the pull off force between 2 oval shapes are referring to the pull off force between fresh fruit bunch with each other and equation (1) use Since fruit has the same substance and radius, R is referring to the radius of the fruit, the work of adhesion assumes to be like equation (3). Other than that, in order to find the radius of the fresh fruit, basic equation of oval shape used as stated below:

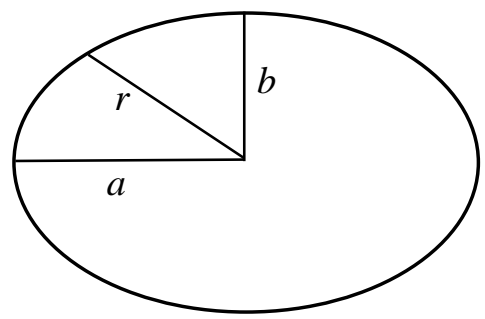

Where $a=$ length, $b=$ width and $r=$ radius 


$$
\frac{x^{2}}{a^{2}}+\frac{y^{2}}{b^{2}}=1
$$

Then substitutes $x=r \cos A$ and $y=r \sin A$ into equation (4) into Cartesian equation as stated below

$$
\begin{aligned}
& \frac{r^{2} \cos ^{2} A}{a^{2}}+\frac{r^{2} \sin ^{2} A}{b^{2}}=1 \\
& \frac{\cos ^{2} A}{a^{2}}+\frac{\sin ^{2} A}{b^{2}}=\frac{1}{r^{2}}
\end{aligned}
$$

Table 3. Radius of Dura and Tenera varieties

\begin{tabular}{|c|c|}
\hline Types & Radius, $\mathrm{m}$ \\
\hline Dura & $0.02256-0.03014$ \\
Tenera & $0.02597-0.03336$ \\
\hline
\end{tabular}

After radius of fruit obtained, the angle values for both dura and tenera determined by using the value of coefficient of friction [3] and surface tension [11] obtained. Table 4 below shows the coefficient friction and angle value of dura and tenera.

Table 4. Coefficient friction and angle values of dura and tenera [3]

\begin{tabular}{|c|c|c|}
\hline & Coefficient of friction, $\boldsymbol{\mu}$ & Angle A \\
\hline Dura & $0.53-0.59$ & $27.9236-30.5406$ \\
Tenera & $0.47-0.57$ & $25.1735-29.6831$ \\
\hline
\end{tabular}

In order to determine the value of surface tension, data presented by Siddiqui and Ahmad (2013) was used and substitute to equations (3)[11]:

Table 5: Values of Surface Tension of Palm Oil Fruit [11]

\begin{tabular}{|c|c|c|c|c|}
\hline $\begin{array}{c}\text { Sample } \\
\text { code }\end{array}$ & Scientific name & $\begin{array}{c}\text { Common } \\
\text { name }\end{array}$ & $\begin{array}{c}\text { Surface } \\
\text { tension } \\
\text { (dyne /cm })\end{array}$ & $\begin{array}{c}\text { Surface tension } \\
\text { /surface energy } \\
\text { (N/m) }\end{array}$ \\
\hline PAM & Elaigsisguinesis Jacq & Palm oil & $5.71+/-0.47$ & $0.00524-0.00618$ \\
\hline
\end{tabular}

\section{Results and Discussion}

The finding of the present study revealed the individual amount of adhesive forces for both dura and tenera varieties which shown in the Table 6: 
Table 6. Values of adhesive forces for dura and tenera varieties

\begin{tabular}{|c|c|}
\hline Contact Point/Surface & F $_{\mathbf{A}}$ \\
\hline between (mild steel) solid and liquid surface for dura & $0.001936 \mathrm{~N}$ \\
between (mild steel) solid and liquid surface for tenera & $0.002129 \mathrm{~N}$ \\
between two ovals for dura & -0.001452 until $0.001936 \mathrm{~N}$ \\
between two ovals for tenera & -0.001597 until $0.002129 \mathrm{~N}$ \\
\hline
\end{tabular}

It was found that, the amount of adhesive force between (mild steel) solid and liquid surface for tenera is much higher compare to dura. This is due to the difference values of radius palm fruit. On the other hand, the amount of adhesive forces between two ovals was obtained. Based on the results in Table 6, the amount of adhesive forces for tenera is much higher compare to dura. Therefore, the stickiness forces of palm fruit can be summarize or simplified in the following equations:

$$
\begin{aligned}
& \mathrm{F}_{\mathrm{s}}=\mathrm{F}_{\mathrm{A} \text { between fruit with fruit }}+\mathrm{F}_{\mathrm{A} \text { between palm oil with mild steel surface }} \\
& \left.\mathrm{F}_{\mathrm{s}}=4 \pi R \gamma+((-3 / 2) \pi R \omega) \text { until } 2 \pi R \omega\right) \\
& \mathrm{F}_{\mathrm{s}}=4 \pi R \gamma+((-3 \pi R \gamma) \text { until } 4 \pi R \gamma)
\end{aligned}
$$

From the equation above, stickiness force is the summation of all adhesives forces which also equals to the summation of the adhesive force between fruit and the palm oil in the surface of mild steel sheet and also adhesive forces between fruit with fruit. Therefore, the amount of stickiness force is actually referring to the summation of adhesive force between solid and liquid surface with the maximum amount of adhesive forces between two palm fruit. Besides, the finding is consistent with finding of past studies by Muhammad Kaleem et.al. (1998) where the maximum force can be used as potential measure of stickiness [12]. Therefore, the amount of stickiness is double up as shown in the equation below:

$$
\mathrm{F}_{\text {stickiness }}=4 \pi R \gamma+4 \pi R \gamma
$$

Table 7 showed the amount of force to stick with one another for 1 fruitlet for tenera and dura are $0.004258 \mathrm{~N}$ and $0.03872 \mathrm{~N}$ respectively.

Table 7. Estimated Stickiness force for 1 spikelet's

\begin{tabular}{cccc}
\hline $\mathbf{F}_{\text {stickiness for 1 spikelets }}$ & 1 fruitlet & $\begin{array}{c}\text { A bunch of 20 kg and 6 g } \\
\text { each fruitlet }\end{array}$ & $\begin{array}{c}\text { A bunch of 40 kg and 20 g } \\
\text { each fruitlet }\end{array}$ \\
\hline $\mathbf{F}_{\text {stickiness for tenera }}$ & $0.004258 \mathrm{~N}$ & $7.0967 \mathrm{~N}$ & $8.516 \mathrm{~N}$ \\
$\mathbf{F}_{\text {stickiness for dura }}$ & $0.003872 \mathrm{~N}$ & $6.4533 \mathrm{~N}$ & $7.744 \mathrm{~N}$ \\
\hline
\end{tabular}




\section{Conclusions}

This paper presented mathematical equations for stickiness force in palm oil fruit for food processing industry. Two conditions of adhesives forces were selected which were adhesive forces between palm fruit and adhesive forces between the fruit and the contact surface area of the machine. The sensitive parameters that was considered in this study are dimension of the fruit, work of adhesion, surface free energy, dynamic angle of repose, coefficient of static friction and surface tension. The total adhesive force applied can be considered as the stickiness forces. In summary, the conclusion drawn from an investigation of stickiness force of palm oil fruit for food processing was:

- The minimum stickiness forces for both dura and tenera varieties determined as $0.003872 \mathrm{~N}$ and $0.004258 \mathrm{~N}$ respectively.

- After finding the stickiness forces of the fresh fruit bunch, the minimum amount of force needed to detach the fruit from the bunches identified. Further research should be taken to investigate different types of forces that might affect the stickiness force for fresh fruit bunch in palm oil mill industry. Apart from that, amount of stickiness force was found to be helpful in improving the threshing and cleaning efficiency. Apart from that, this information is very crucial for the thresher designer in order to improve the quality performance of the thresher machine in palm oil mill industry.

\section{References}

[1] Sime Darby, "Palm Oil Facts \& Figures," April 2014, vol. 2012, 2014.

[2] B. Adhikari, T. Howes, B. R. Bhandari, and V. Truong, "Stickiness in Foods: a Review of Mechanisms and Test Methods," Int. J. Food Prop., vol. 4, no. 1, pp. 1-33, 2001.

[3] O. K. Owolarafe, M. T. Olabige, and M. O. Faborode, "Physical and mechanical properties of two varieties of fresh oil palm fruit," J. Food Eng., vol. 78, no. 4, pp. 1228-1232, 2007.

[4] S. A. Fatin and S. Rosnah, "Effect of chopping oil palm fruit Spikeletes on the free fatty acid content release rate and its mechanical properties," pp. 511-516, 2014.

[5] R. G. Polytechnic and O. State, "Performance evaluation of a palm fruit,” vol. 5, no. 9, pp. 29-33, 2010.

[6] F. Gully, "Physical Aspects of Fruit Growth," pp. 585-590, 1982.

[7] C. Atwood-Stone and A. McEwen, "Measuring Dynamic Angle of Repose in Low Gravity Enviornments Using Martian Sand Dunes," LPI Contrib., pp. 30-31, 2013.

[8] G. A, Rowland, "A material used for bonding that exhibits flow at the time of application.," Adhes. Adhes., pp. 1-11, 1998.

[9] M. Farshchi-Tabrizi, M. Kappl, Y. Cheng, J. Gutmann, and H.-J. Butt, "On the adhesion between fine particles and nanocontacts: an atomic force microscope study.," Langmuir, vol. 22, no. 5, pp. 21712184, 2006.

[10] N. K. Adam and H. K. Livingston, "Contact Angles and Work of Adhesion,” Nature, vol. 182, no. 4628, pp. $128-128,1958$.

[11] N. Siddiqui and A. Ahmad, “A study on viscosity, surface tension and volume,” vol. 2, no. 6, pp. 13181326, 2013.

[12] M. Kaleem, J. D. Satterthwaite, and D. C. Watts, "A method for assessing force/work parameters for stickiness of unset resin-composites," Dent. Mater., vol. 27, no. 8, pp. 805-810, 2011. 


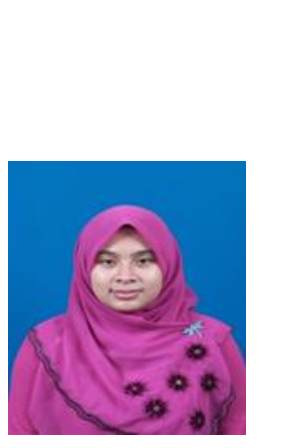

\begin{abstract}
Authors

\section{Sherena Bt Saree}

Sherena Bt Saree is a postgraduate student, attached to the Department of Chemical Engineering And Energy Sustainability, Faculty of Engineering, Universiti Malaysia Sarawak (UNIMAS).
\end{abstract}

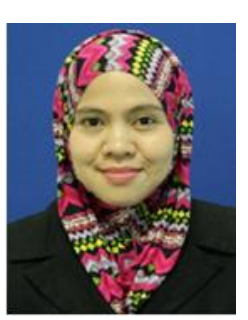

\title{
Shanti Faridah Salleh
}

Dr. Shanti Faridah Salleh is a lecturer, attached to the Department of Chemical Engineering and Sustainability Energy, Faculty of Engineering, Universiti Malaysia Sarawak (UNIMAS). She received her doctorate at Universiti Pertanian Malaysia (UPM) in 2010 and she is now the Head of Chemical Engineering Department.

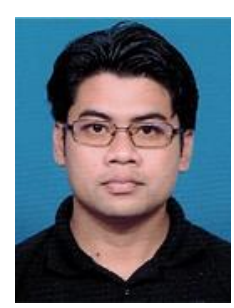

\section{Mohd Azlan Ismail}

Mohd Azlan Ismail is a PhD candidate in University Malaysia Sarawak with research interest in Sustainable Energy. He graduated from University Malaysia Sabah and has a Master Degree in Mechanical Engineering Practice from University of Wollongong, Australia. He is also a graduate member of Institute of Engineers, Malaysia. 